\title{
DA PRENDA A MULHER \\ levolução da imagem feminina via poesia regionalista do \\ Rio Grande do Sul)
}

\author{
LISANA BERTUSSI
}

Saint-Hilaire, viajante francês, que esteve no Rio Grande do Sul, no século XIX, em seu Viagem ao Rio Grande do Sul, 1 destacou a mulher gaúcha da imagem depreciativa que imputava à brasileira em geral, quando comparada com a européia, porque percebeu que aqu ... "As senhoras conversavam sem constrangimento com os homens" 2 e não se ocultam como em outras regiø̄es quando chega o visitante masculino.

Essa potencialidade de fala, que o meio não sufocava inteiramente, dava então à gaúcha um lugar à parte no cenário nacional, segundo o cronista.

No entanto, hoje, um dos mais polêmicos críticos do movimento tradicionalista, Tau Golin, em seu Por baixo do poncho 3 diz:

... os tradicionalistas institucionalizaram uma palavra que expressa realmente o conceito social e emocional que possuem em relação à mulher: "prenda". O seu significado qualquer dicionário nos dá: acessório, adorno, coisa que se possui, que se usa, se ocupa, etc.,

o que contradiz a percepção de Saint-Hilaire quanto às possibilidades femininas.

Vamos então tentar observar que percurso é este da evolução da imagem da mulher gaúcha, de prenda à mulher, qual o papel da Poesia regionalisti neste processo, se, por um lado ela, a literatura, retratou a realidade feminina, denunciando criticamente a condição da mulher, se estimulou uma caminhada rumo à emancipação ou se por outra reafirmou a ideologia romàntiait que a mascara.

No século XIX, na literatura oral, no Cancioneiro gaúcho, 4 compilação de Augusto Meyer, temos o "Tatu", motivo de fandango popular, em que o lierói é o homem haragano, que corre mundo com liberdade, por trinta e tantis estrofes, pretensamente sem vínculos familiares, mas que, no final, desvelase como marido e pai de vários tatuzinhos, e voltando machucado do perurso, espera que a tatua, que só então é nomeada, faça o papel da tradicional enformeira que cuida do seu nomem. E o tatu é ainda pretensioso, desafiando a mulher no sentido de substituí-la se ela não assumir este papel:

I Lana Bertussi é professora na Universidade de Caxias do Sul (RS).

IFAINT-HILAIRE, Auguste, Vlagem ao Rio Grande do Sul. Porto Alegre, Martins, 1987. 14. 0.66 .

Col IN, Tau, Por baive do poneho, Porto Alegre, Tchê, 1987.

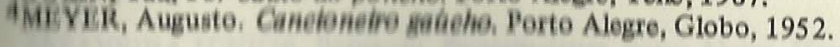


Se quiser curar, me cure,

Não the faltando vontade

Que senáo eu vou-me embo

Lá prá casa da comadre.

O tatu morre e, curiosamente, a tatua que sobrevive a ele, mesmo necessitando substituir o marido, passa por uma transformação pois permite-se uma escolha consciente. Diz o poeta:

\section{A tatua está mitrada}

Quer marido doutro jeito

Que não viva longe dela

Seja um tatu de respeito.

Noutro motivo de fandango, a "Chimarrita", temos já a mulher coletivizada como velha ou pobre, mas que, sonhadora, inventa um mundo mentiroso e melhor:

\section{Chimarrita é altaneira}

ão quebra nunca o corincho

Diz que tem trinta cavalos

Nesta composição, temos o homem-poeta, cantando a mulher, a pedido de uma moça, gesto do qual, no final, espera o seu "galardão", e portanto, não é gratuito. A chimarrita morre, mas sua morte e vida são produtivas porque dão motivo para se pensar:

\section{Chimarrita morreu ontem \\ E ainda hoje tenho pena \\ Do corpo da Chimarrita \\ vi corpo da Chima \\ Chimarrita morreu ontem \\ Mas há sempre que durar; \\ As penas da Chimarrit \\ Fazem a gente pensar.}

Ainda, na literatura oral, a composição intitulada "O balaio", de origem nordestina, expressa o preconceito do mito da virgindade, limite imposto mulher pela ordem social que lhe recorta um mundo diminutivo e fechado:

Recorta, meu bem recorta

recorta o teu bordadinho

Depois de bem recortado

Derais no teu balainho 9

idéia de opressão reforçada pelo enfoque dado à questão da infidelidade de conjugal, proibida à mulher, a quem não se permite, por outro lado,

\section{Id. \\ 6Ibid. \\ 7Ibid. \\ 8Ibid. \\ 9Ibid.}

mencionar a infidelidade masculina. Observem-se, respectivamente, as quadrinhas de "Galinha morta" e "Despedida":
A galinha e a mulhe
Não se deixa passea
A galinha o bicho come
A mulher, dá que falar.
Quero dar a despedida
Como deu a Saracura
Os ciúmes da mulher

Com o chicote é que se cura. 11

Repare-se, por outra, como a mulher é considerada objeto do mundo masculino, inclusive ocupando posição menos elevada que aquela do cavalo

\section{Estou velho tive bom gosto \\ Morro quando Deus quiser \\ Duas penas levo comigo
Cavalo bom e mulher. 12}

E é curiosissimo como o poeta, ao considerar a mulher como "prenda" do seu amor, distorce essa realidade, invertendo os papéis de ambos, homem e mulher, para colocar-se, falsamente, na posição de escravo:

\section{A fita do teu cabelo \\ Ébuçal maneia e laço \\ Descogotado e lunanco \\ Inda por ti movo o passo. 13}

Registrável é a enfática quase ausência da figura feminina, no Cancioneiro da Revolucão de 1835,14 compilado por Apolinário Porto Alegre, em que os homens são os únicos grandes heróis, quando sabemos da importante participação da mulher, que cuịdava da estância na ausência do marido, doava bens à Revolução, confeccionava uniformes, quando não tinha um papel ainda mais relevante, acompanhando os homens na guerra, lutando como Anita Garibaldi, ou participanao como espiã. Apesar disso, este Cancioneiro mostra a mulher como vaga referência do homem saudoso do lar, ou apenas como procriadora de soldados. Observe-se:

No romantismo, essa imagem apequenada da mulher não sofre transformações e até é reforçada. Bernardo Taveira Júnior, em Provincianas, 16 ao lado do engrandecido herói masculino que é o vaqueano, o boleador, laçador, o domador e outros desdobres, sempre apológicos, abre espaço dimmuto para a mulher, em pouquíssimos momentos, em que ela é figura frágil e miniaturizada. Observe-se a composição "O casamento":

\section{IUIbid. \\ 11 İid.}

12 ibid.

13ibid.

4 FORTO ALEGRE, Apolinário, Caneioneiro da Kevolução de 1835. Porto Alegre, Cia. Uniao de seguros, 1981.

$151 d$

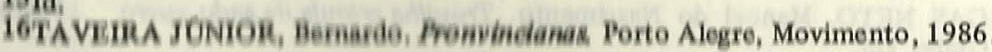


Lá vem montada em seu formoso

Rocim, altivo e brioso

A noivinha que a seu noivo

Entregou seu coração.

É belo da camponesa

Ver-se leve e com destreza

o pezinho menear-se

Ver-lhe o corpinho flexível

Com graca indescritivel 17

(os grifos são nossos)

em que à "noivinha" se opõe o rocim "formoso", "altivo" e "brioso",

No século $\mathrm{XX}$, inicialmente, a poesia reafirma pela imagem feminina, a ideologia machista que a considera como "prenda", objeto secundário no universo masculino, mas haverá agora um percurso evolutivo que acabará por delineá-la mulher por inteiro.

Em Augusto Meyer, ela é ainda imagem vaga, pretexto para falar dos sentimentos do poeta, ou reforçada sua falta de identidade, a mulher é vista apenas parcialmente por uma qualidade exterior: a aparência. Observe-se poema, não gratuitamente, intitulado "Bonita":

Bonita, Bonita

quem foi que te achou

Ninguém não me acho

meu bem Madrinha

meu bem não chego

Bonita, Bonita

Não vês quem, chegou

num carro de prata

com vinte tordilhos.

Na volta da estrada

que nuvem de poeira

em que, na "Bonita", que só é identificada se for "achada" pelo homem, temos esboçada a tradicional figura da cinderela, já tão carregada de conotação ideológica machista.

Em Vargas Neto, no seu Tropilha crioula e gado xucro,19 a mulher é figura acessória, coletivizada despersonalizada na "china", sem nome, elemento secundário do mundo masculino, em que ressalta-se o homem como o indio vago, o andarengo, que lhe dedicam um amor egoísta, expresso numa relação de uso e descomprometimento. Observe-se o poema "Negada".

Eu não agüiento a carona

Que o teu capricho reque

Sempre fui passarinheiro

Pra volteio de mulher.

Não largues a tava pra mim

17 Id

18MEYER, Augusto, Poemas de Bilu. In: Poesias. Rio de Janeiro, Livraria São José, 1957.

1957. Alegre, Globo, s/d.

Organon $16 / 1989$
Que não engordas a chiba

Mesmo que "mosca de venda"

Só bebo canha de arriba...

(o grifo é nosso)

Em Aureliano de Figueiredo Pinto, embora apareçam poucos poemas dedicados à mulher, os sentimentos femininos já começam a ser motivo de poesia e, de sua figura plana, passiva e dócil, anteriormente configurada, começa a delinear-se uma maior esfericidade através da emersão de traços autênticos de espontaneidade primitiva, como em "Cria velha":

Linda macia, morena

mais mansa que mate doce

que a gente perto se baba.

Ah! ... Amigos !quando embrabece

a bugra antiga aparece

peleando à porta da taba., 21

em que a raiva agressiva, opondo-se à docilidade e mansidão, dá identidade humana à mulher.

Ainda, no mesmo poeta, percebe-se a preocupação com a mudez feminina e o autor poetiza o estímulo à sua fala em "Toadas da noite linda":

\section{E eu penso... se elas cantassem sob as ramad as}

que não diriam do amor dos andarengos!

Se elas abrissem uma cordeona sob as estrelas

que funda angústia não lhes viria

na voz sem eco pelo silêncio dos que se foram e não voltaram...,22

mas são apenas raros momentos de sua poesia, porque Aureliano tem verdadeiras recaídas machistas como se pode ver em "Fogo do diabo":

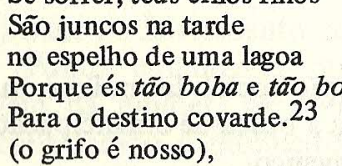

em que a passividade é elogiada em "tão boa" e "tão boba", ou ainda na "Décima do Despachado", em que a mulher é vista, nada menos do que como "bonecra", brinquedo do gaúcho.

Já, em Apparício Silva Rillo, há um importante salto em direção ao desmascaramento da condição real da mulher que a prenda oculta e vela. Ouçamo-lo em Cantigas de tempo velho:

Chinoca que a legenda dos poemas

fez morena, fez bonita

chita

cabelo sempre trançado,

20 Id.

21 PINTO, Aureliano Fiqueiredo, Romances de estância e querência - marcas do tempo . Perto Alegre, Marinint 19 ili

$221 \mathrm{~d}$.

2.jolic

Oกgaลอก 16/1989 
na trança sempre uma flor.

Chinoca que o embalo das cantigas

fez esguia como os juncos,

de olhos grandes cor da noite,

boca sempre de pitanga

cor quí senpre fell...

por que será que os poetas

por que sera que as cantigas

e o poeta inclusive dedica todo um livro só para a mulher. É o "Itinerário de Rosa",25 título em que se ironiza a tradicional configuração da prenda como flor, enfeite, adorno. Rosa é anti-heroína coletiva e já, no poema "Portal", explicita-se-a como:

Um símbolo direis de tantas quantas
- iguais rota e derrota, linha e traço. 26

E o texto que Apparício chamou de "novelinha passional" conta a estória de uma adolescente campeira que, perdendo a virgindade, é expulsa de casa e acaba por protistuir-se na cidade. Mas, mesmo neste universo de degradação, Rosa sonha com uma vida melhor que lhe é negada, pois sua condição evolui para um impasse trágico em que a pobreza é reforçada pela perda de valor como mercadoria, com a chegada da velhice. E mais uma vez Rosa é expulsa do mundo. Observe-se o poema "Transição":

\section{Balaio de anos pesados \\ Seios frouxos, celulite \\ A cicatriz disfarçada \\ nas rugas fundas da cara \\ De rosinha foi a Rosa,}

Desta forma, o poeta desvela a degradação social da mulher, mas não há ainda aqui a poetização de um estímulo para a busca de emancipação, mesmo que tenhamos, sem dúvida, um respeitável avanço.

Será um movimento musical, a Califórnia da Canção nativa de Uruguaiana, que, abrindo espaço para a poesia, cumprirá o papel de estimulador do processo de libertação feminina.

Já, nos primeiros festivais, denunciou-se a condição limitada da mulher no universo machista. Observe-se a música "Janaíta" de Claudio Boeira Garcia e José Valdir S. Garcia:
Janaíta sete irmão
Janaíta pai peão
Janaíta, não diz nâo
Janaíta, não diz não.

24RILlO, Apparício Silva. Cantigas de tempo velho. Porto Alegre, Martins, 1981. 25_. Itinerário da Rosa. Porto Alegre; Martins, 1983.

26 Id.

27Ibid. ou a "Leontina das Dores" de Luiz Coronel e Marco Aurélio Vasconcelos:

Pra dentro Maria Leontina

Menina não vai pro galpão

Leontina de quarto e sala

u ainda "Maria... Maria" de Pedro Emílio Rocha:

\section{Maria que é preta, Maria que é branca \\ Maria que é pobre, Maria que é rica \\ Maria que varre o rancho cantando \\ Maria que fica socando cangica}

Maria querida, imagem do Pampa.

em que a ironia é clara na coletivização da miséria feminina.

Mais recentemente, a conhecida letra da música "Campesina" de Sérgio

Napp e Mário Barbará, fará importante papel desmascarador, ao trabalhar com a contraposição de dois discursos paralelos: o do poeta, crítico desvelador da situação real e do gaúcho machista, mistificador. Primeiramente, fala o poeta da mulher:

Bate a roupa, torce o corpo, enreda o campo

bebe o sonho, esfrega a vida, enxuga o tempo,

foge o riso, enrola o sonho, esfrega os olhos,

torce a vida, bate o medo, esfola as mãos.

e, em seguida, o campeiro:

Que mulher valente, buena companheira

Suas mãos são asas, seu olhar me guarda

Que mulher valente, buena companheira

me repara a casa e me enfeita a cama

(o grifo é nosso),

que insiste no falseamento do sofrimento feminino.

Ponto culminante do percurso de poetização da emancipação da imagem da mulher, na poesia regionalista e do Rio Grande do Sul, pode ser considerado o momento em que a mesma abre espaço para a sua fala, na poesia, adquirindo por um lado plena consciência de seus papéis sociais, por outro, desmistificando o feminismo estereotipado e reclamando uma participação efetiva e madura no mundo. Observemos "Mulher", música de Sérgio Napp e Marlene Pastro:

\section{As mãos que afagam o teu corpo \\ também te curam as ferida \\ a mesma boca que beijas \\ serviu de aviso as intrigas \\ Contigo laviei essas terras \\ com meus braços de alegria \\ não abro mão dos meus dengo \\ buscando minha alforria \\ So $\mathrm{em} \mathrm{mim}$ apagas teu fogo \\ o o tou gozo de viver \\ vou feita do meimo barro \\ tambem quero ter prazar. \\ Matel a sede que tinhas}


domei as tuas canseiras

plantei, pari, fui teu pouso

não sou rama, sou figueira.

Me enfeito pro teu agrado

me entrego se me acarinhas

me nego se vens de espora

me querendo por bainha

Por certo não fui criada

apenas para ser fêmea

ou prá enfeitar teus fogões

quero ser tua alma gêmea. mesmo!

Pena Saint-Hilaire não estar aqui para ver que a mulher gaúcha fala 